Henry Antonio Mendoza Tolosa"

Jacobo Campo Robledo*"

Universidad Católica de Colombia Bogotá, Colombia

Recibido: 23 de noviembre de 2015

Concepto de evaluación: 18 de mayo de 2016

Aprobado: 20 de octubre de 2016

Artículo de investigación

(C) 2017 Universidad Católica de Colombia.

Facultad de Ciencias

Económicas y Administrativas.

Todos los derechos reservados

* Magíster en Ciencias Económicas.

Docente e investigador del

Grupo Finanzas y Política

Económica, Facultad de Ciencias

Económicas y Administrativas,

Universidad Católica de

Colombia. Bogotá, Colombia.

Dirección de correspondencia:

carrera 13 \# 47-30, Universidad

Católica de Colombia, Facultad de Ciencias Económicas y Administrativas, Bogotá,

Colombia. Correo electrónico: hamendoza@ucatolica.edu.co

** Magíster en Economía. Docente e investigador del Grupo Finanzas y Política Económica, Facultad de Ciencias Económicas y Administrativas, Universidad Católica de Colombia,

Bogotá, Colombia. Dirección de correspondencia: carrera 13 \# 47-30, Universidad

Católica de Colombia, Facultad de Ciencias Económicas y Administrativas, Bogotá,

Colombia. Correo electrónico: jacampo@ucatolica.edu.co
Finanz. polit. econ., ISSN: 2248-6046, Vol. 9, No. 1, enero-junio, 2017, pp. 113-134

http://dx.doi.org/10.14718/revfinanzpolitecon.2017.9.1.7

\section{Localización y especialización productiva regional en Colombia*}

\section{RESUMEN}

Este artículo busca responder si las economías regionales colombianas fueron objeto de reconstitución en sus estructuras productivas entre 2000 y 2014 , y de haberse dado, representar en qué sentido dicho proceso ha sido eficiente para los diferentes departamentos, desde los resultados y la dinámica de sus actividades económicas. Para ello, se ha recurrido a la aplicación de una serie de indicadores estadísticos particulares en el estudio de la geografía espacial, entre los que se destacan el análisis factorial bajo el método de componentes principales para explicar la orientación productiva regional; asimismo, se utilizaron en forma complementaria los índices sintéticos de especialización productiva regional, para analizar la dinámica de la diversificación productiva departamental. Los resultados de la presente investigación muestran que buena parte de las regiones colombianas han venido diversificando su actividad económica en franca orientación a las actividades de servicios, entre las que, sin embargo, son representativos los servicios de gobierno y de no mercado producidos por estas instituciones, dejando progresivamente de depender de unas escasas y concentradas fuentes de crecimiento, contrario a otras en las que ha sido y sigue siendo el sector primario — particularmente el minero- el eje dinamizador de las estructuras productivas. Con ello, se ha retrasado el proceso de diversificación acorde con las demandas locales y un orden económico internacional que las requiere, en la medida del paso del tiempo, con mayor intensidad. espacial.

Palabras clave: PIB regional, especialización productiva, economía JEL: H72, R10, R50.

\section{Location and regional productive specialization in Colombia}

\section{ABSTRACT}

This document is directed to responding if Colombian regional economies restructured their productive activities from 2000 to 2014, and if so,

\footnotetext{
Este artículo es resultado de un proyecto de investigación orientado a estudiar los determinantes de la dinámica económica regional, propuesto y desarrollado en 2015 por el grupo de Finanzas y Política Económica de la Facultad de Ciencias Económicas de la Universidad Católica de Colombia.
} 
illustrate the way that process has been effective in the different departments from the results and dynamics of their economic activities. For developing this exercise, we used a set of statistical indicators of spatial geography, among which is the factorial analysis, specifically the method of principal components, whose purpose was to identify the set activities whose performance explains more clearly the productive orientation of the departments, and complementary synthetic regional specialization indexes were employed in order to identify the degree and the changes of economic diversification, presented in those indicators. The results of this research shows that most of the Colombian regions have diversified their economic activity, with focus on service activities, among which are representative government and non-market services produced by those institutions, nowadays less dependent on few sources of growth. However, in other regions the primary sector, mainly mining activity, for many years has been the most important activity of production structures, affecting the process of full diversification, which is close to current local demands and international economic order the requests with greater intensity.

Keywords: Regional GDP, productive specialization, spatial economics.

\section{Localização e especialização produtiva regional na Colômbia}

\section{RESUMO}

Este artigo procura responder se as economias regionais colombianas foram objeto de reconstituição de suas estruturas produtivas entre 2000 e 2014, e, se sim, representar em que sentido esse processo foi eficiente para os diferentes estados, a partir dos resultados e da dinâmica de suas atividades econômicas. Para isso, recorreu-se à aplicação de uma série de indicadores estatísticos particulares no estudo da geografia espacial, entre os quais se destacam a análise fatorial sob o método de componentes principais e os índices sintéticos de especialização produtiva regional. Os resultados da presente pesquisa mostram que boa parte das regiões colombianas vem diversificando sua atividade econômica em franca orientação às atividades de serviços, entre as quais, contudo, são representativos os serviços de governo e de não mercado produzido por essas instituições, o que deixa progressivamente de depender de umas escassas e concentradas fontes de crescimento, contrário a outras em que continuam sendo o setor primário — particularmente a mineração-o eixo dinamizador das estruturas produtivas. Com isso, tem sido atrasado o processo de diversificação plena em consonância com as demandas locais e com uma ordem econômica internacional que as demanda, com o passar do tempo, com maior intensidade.

Palavras-chave: economia espacial, especialização produtiva, PIB regional. 


\section{INTRODUCCIÓN}

La geografía económica y el análisis espacial vienen tomando fuerza como métodos de análisis de las dinámicas productivas de los países, particularmente porque es a través de la comprensión de las asimetrías, capacidades y potencialidades regionales como pueden orientarse mejor las políticas públicas que promuevan un verdadero desarrollo y bienestar. Los estudios para determinar la dinámica originada por la distribución espacial de la producción en la economía se han enfocado en el análisis de la especialización y la localización de la actividad, mediante el uso de indicadores estadísticos que contrastan las diferentes tipologías de producción de un territorio asociado, así como del total del país, que en dichos escenarios se asume como el punto de referencia general.

En este sentido, diferentes estudios se han formulado desde la construcción de índices sintéticos de especialización productiva o de localización espacial de la actividad económica, con base en los planteamientos pioneros de Boissier (1980), uno de los autores más destacados. De manera más reciente está el trabajo de Arias y Fortich (2010), entre otros autores, cuyos indicadores ilustran de manera efectiva la ruta de orientación de las unidades económicas, de forma tal que el diseño de políticas y la toma de decisiones sean útiles en la organización de las estructuras productivas.

Pons y Tirado (2009), en un análisis de las regiones europeas, haciendo mención, entre otros, a los casos de España, Italia, Grecia y Portugal, determinaron una relación negativa entre la especialización productiva y la dinámica del ciclo en sus regiones. Encontraron que hay marcadas influencias de territorios específicos en el comportamiento general de sus economías; por ello, señalan que cuando se presenta especialización productiva en una región, los vecinos más cercanos se convierten en fuente de asimetrías no solo en su entorno próximo, sino también para el total del territorio.

Asimismo, Rodríguez (2005), en un análisis de especialización de las economías europeas a partir del contraste de estos indicadores en los sectores agrícola, industrial y de servicios, dejó expedito el espacio para el diseño de políticas comunitarias focalizadas en la movilidad de los factores y productos para los países de la Unión Europea, de modo tal que fuera posible direccionarlos a los espacios geográficos en los que el retorno económico efectivo les era más benéfico.

Para el caso de la economía colombiana, el trabajo de Sánchez (2006) ofrece luces sobre el comportamiento de la especialización sectorial y regional. El autor explica cómo entre 1975 y 1998 existió homogeneidad en el crecimiento económico departamental, y aporta evidencia en el sentido de que los servicios constituyeron para el periodo analizado las actividades con mayor dinámica e impacto transversal en la estructura productiva.

Asimismo, Mendoza y Campo (2014) estudiaron el impacto del gasto y la inversión públicas en el crecimiento económico de los departamentos en Colombia, con base en las Cuentas Nacionales para el periodo 2000-2013; sus resultados evidenciaron una influencia fuerte del gasto público en el producto interno bruto (PIB) regional, más intensivo en regiones menos desarrolladas, pero más efectivo y mejor utilizado en los polos de crecimiento económico; todo como resultado de una mejor administración y focalización del presupuesto local. De igual manera, advirtieron que las regiones con mejores índices de localización geográfica de la inversión productiva, superiores al promedio nacional, la han intensificado preferentemente en obras civiles, para dinamizar las actividades mineras y energéticas, y no en la diversificación productiva propia del aporte que hacen las economías más grandes.

Por su parte, Mendoza y Yanes (2014) identificaron una influencia importante del gasto público en las entidades territoriales, particularmente en las economías de menor tamaño del PIB. Así, estas hicieron del gasto público un motor original de la actividad, y con ello lograron que dichos territorios estuvieran especializados en la oferta de servicios públicos, más que otras regiones. Al igual que Hernández (2009), deducen que más que el volumen del gasto público, es su orientación lo que lo 
hace más efectivo para impulsar el desarrollo de la producción local.

Dichas contribuciones condujeron a que el objetivo central y problema de esta investigación consistiera en identificar si las economías regionales entre 2000 y 2014 se han especializado, o si por el contrario han entrado en la ruta de la diversificación productiva, en línea con los cambios que ha presentado la dinámica mundial de los negocios, así como con el interés de los inversionistas que ven ahora a Colombia como un país emergente y con una economía sólida que atrae capitales no solo a los polos de desarrollo convencionales, sino a un número cada vez mayor de departamentos.

Para responder al propósito fundamental de este trabajo, se desarrolló una metodología que combina dos alternativas conducentes a caracterizar el cambio estructural de las economías regionales. El trabajo articula varias técnicas de análisis estadístico que incluyen, por un lado, la medición del fenómeno mediante la elaboración de indicadores espaciales de especialización productiva y, por otro, el análisis factorial como opción complementaria. A partir de los resultados obtenidos se identificaron las actividades económicas que constituyen la base estructural del sistema en cada año seleccionado, y se evaluaron conjuntamente durante dicho lapso; para ello, se utilizaron como fuentes las cuentas nacionales departamentales, la existencia de cambios en la dinámica productiva regional y su relevancia para las regiones y los sectores involucrados.

La metodología adoptada contempló dos fases complementarias. En la primera se desarrolló un modelo de análisis de componentes principales (ACP), con el fin de determinar para cada periodo, y entre la canasta de actividades productivas, cuáles de ellas han impulsado en mayor o menor medida los resultados de la especialización productiva regional. La segunda fase, tomando como referente los resultados obtenidos en el proceso previo, consistió en construir y contrastar los coeficientes de especialización productiva local de las diferentes actividades económicas, a fin de determinar si las economías regionales entre 2000 y 2014 se han diversificado, o si por el contrario han concentrado su dinámica en ciertas actividades específicas.

En atención a lo descrito, el artículo fue estructurado de la siguiente manera: en el primer apartado se describe la metodología empleada, particularmente las técnicas y el instrumental seleccionados para resolver el problema de investigación; a continuación se explican los resultados obtenidos durante el estudio y se contrastan las diferentes cifras, con el fin de ilustrar los aspectos y hallazgos particulares de este análisis de la economía espacial colombiana; en la última parte se abre la discusión en torno a las reflexiones obtenidas y los resultados de la investigación.

\section{METODOLOGÍA}

La identificación del perfil económico de las unidades subnacionales en Colombia contempló tres procesos independientes, aunque complementarios entre sí, cuyo fin fue determinar los cambios estructurales y comenzar a delinear la orientación productiva local del país en el periodo analizado. En primer lugar, se ilustran los resultados generales del PIB departamental, mediante el uso de indicadores descriptivos básicos de evolución en tamaño, composición y estructura de las economías regionales, así como de dinámica y contribuciones al crecimiento en el total del territorio de las actividades productivas primarias, secundarias y terciarias.

La segunda fase abordó el diseño de un modelo de análisis factorial por regiones y actividades económicas, con el propósito de simplificar el conjunto de sectores que determinan la estructura y dinámica productiva de los departamentos en Colombia, de manera que se facilite la interpretación de dicha información. En la medida en que hay varias metodologías relacionadas con este tratamiento estadístico, se seleccionó el método de análisis de componentes principales (ACP), en razón a que dicha técnica estadística permite estimar, a partir de grupos ampliados de variables, un número reducido de componentes que explicaran en un alto porcentaje la disposición productiva de las economías departamentales. 
Con el proceso de análisis factorial se recreó, desde el valor agregado de todas las regiones y sus actividades económicas, una combinación lineal de dichos resultados, que se simplificaron a una serie reducida de componentes que las contienen, facilitando así su interpretación. En tal caso, el modelo ACP viene representado por esta función:

$$
Y n=\sum_{i=1}^{n}\left(a_{h k} * X_{h k}\right)
$$

Donde $Y_{n}$ representa cada una de las $(n)$ componentes que constituyen la combinación lineal de las $(K)$ variables de análisis, conforme los atributos específicos por estudiar en estas $(h)$ y que se presentan en un periodo $(t) ; a_{h k}$ corresponde a los valores propios $(n)$ que identifican el coeficiente de explicación de una variable $(k)$, según el atributo $(h)$ en el componente asociado $(Y n) ; X_{h k}$ identifica los datos de cada una de las variables de análisis $(k)$, según su atributo específico $(h)$ y en un periodo $(t)$.

Por tanto, las componentes que explican la estructura del PIB por actividad económica están representadas por la notación:

$$
\begin{aligned}
& Y 1=a 11 X 1+a 12 X 2+\ldots . a 1 h X k \\
& Y 2=a 21 X 1+a 22 X 2+\ldots . a 2 h X k \\
& Y 1=a 11 X 1+a 12 X 2+\ldots . a 3 h X k \\
& Y n=a n 1 X 1+a n 2 X 2+\ldots . a n h X k
\end{aligned}
$$

Donde $Y_{n}$ representa cada una de las componentes que son resultado de la combinación lineal del valor agregado departamental $\left(X_{k}\right)$ de un periodo $(t)$, que en este último caso, a efectos de contraste intertemporal, consideró en ejercicios independientes los resultados del PIB departamental de 2000 y 2014. Por su parte, $a_{n h}$ representa el valor propio generado por cada componente $Y_{n}$ al nivel cada actividad económica $(h)$ por región.

A partir de los resultados obtenidos se dispone de parámetros estandarizados de referencia para interpretar la vocación económica de las regiones. Estos parámetros son utilizados como insumo de estudio con mayor precisión en la última fase: la elaboración del índice sintético de especialización departamental (ISED), con el cual se interpreta, a partir de la combinación de resultados por actividad económica, si la orientación productiva es especializada o diversificada en cada región.

En tal sentido, el ISED se define mediante la siguiente relación:

$$
I S E D_{j}=\frac{1}{2} \sum_{i}^{n} \cdot\left|\cdot \frac{x_{i j}}{\sum_{i} X_{i j}}-\cdot \frac{\sum_{j} X_{i j}}{\sum_{j} \Sigma X_{i j}}\right|
$$

Donde $X_{i j}$ representa el valor agregado de cada actividad económica $(i)$ en un departamento $(j)$.

La notación del ISED refleja en valores absolutos el agregado conformado por la diferencia entre el peso de cada una de las actividades económicas en un departamento y la participación de estas en el PIB nacional. Una región es especializada en un sector cuando su valor agregado es más representativo que en otro territorio o en la economía nacional. En el ISED, cuyos coeficientes oscilan entre cero $(0)$ y uno (1), esto se aprecia cuando el índice de especialización es mayor en un territorio que en otro o respecto al país; es decir, si tiende a uno (1), se infiere que la región es especializada en una actividad productiva, en varias o en todas respecto a otra región o al país, según se defina el contexto de comparación.

Si esto último sucede en el agregado de todos los sectores productivos, se afirmará entonces que el departamento es especializado; en forma contraria, en la medida en que dicho indicador tienda a cero o su resultado sea inferior al de otra entidad territorial, se puede afirmar que allí hay una mayor diversificación productiva.

\section{RESULTADOS}

Los resultados de este trabajo se describen desde diferentes frentes secuenciales complementarios entre sí, a efectos de dar respuesta al objetivo general. En primer lugar, se presenta una descripción general de los indicadores más representativos de las cuentas nacionales departamentales, con el fin de plasmar aspectos centrales de su tamaño, estructura, crecimiento del valor agregado, 
territorios líderes y actividades predominantes para el periodo 2000-2014. A continuación, con el fin de determinar el perfil económico regional del país en un conjunto reducido de actividades y concentrar el análisis en los territorios de mayor impacto, se presentan los resultados de un modelo de análisis factorial (ACP) que hace referencia a los componentes principales por sector económico que han influido en mayor medida en la dinámica productiva de los departamentos en Colombia, así como la influencia que han ejercido en el comportamiento de su aparato empresarial.

Los resultados obtenidos en las dos fases previas se refuerzan con la lectura de los ISED, de cuya interpretación se busca identificar si en el periodo 2000-2014 las regiones experimentaron un proceso de diversificación en su portafolio de actividades económicas, o bien, si se concentraron en la producción especializada de unos pocos sectores.

\section{Comportamiento del producto interno bruto departamental, 2000-2014}

El producto interno bruto (PIB) colombiano presentó durante el 2000 un valor de $\$ 208.531$ miles de millones de pesos, y en 2014 de $\$ 756.152$ miles de millones de pesos, lo que significa que la economía nacional es ahora 3,63 veces más grande que en 2000. De este patrón se destaca la dinámica que durante los últimos quince años presentó Meta $(9,46$ veces más grande que en el 2000$)$, seguido de Putumayo (mayor en 5,67 veces), Santander (mayor en 4,92 veces), Cesar (mayor en 4,82 veces) y Cauca (mayor en 4,42 veces), entre otros. Este comportamiento superó en evolución el tamaño de la economía nacional (gráfica 1).

No obstante lo anterior, en términos generales las economías regionales mantuvieron su participación en el PIB entre 2000 y 2014. Bogotá

Gráfica 1.

Cambio en el tamaño de las economías departamentales (2000-2014)

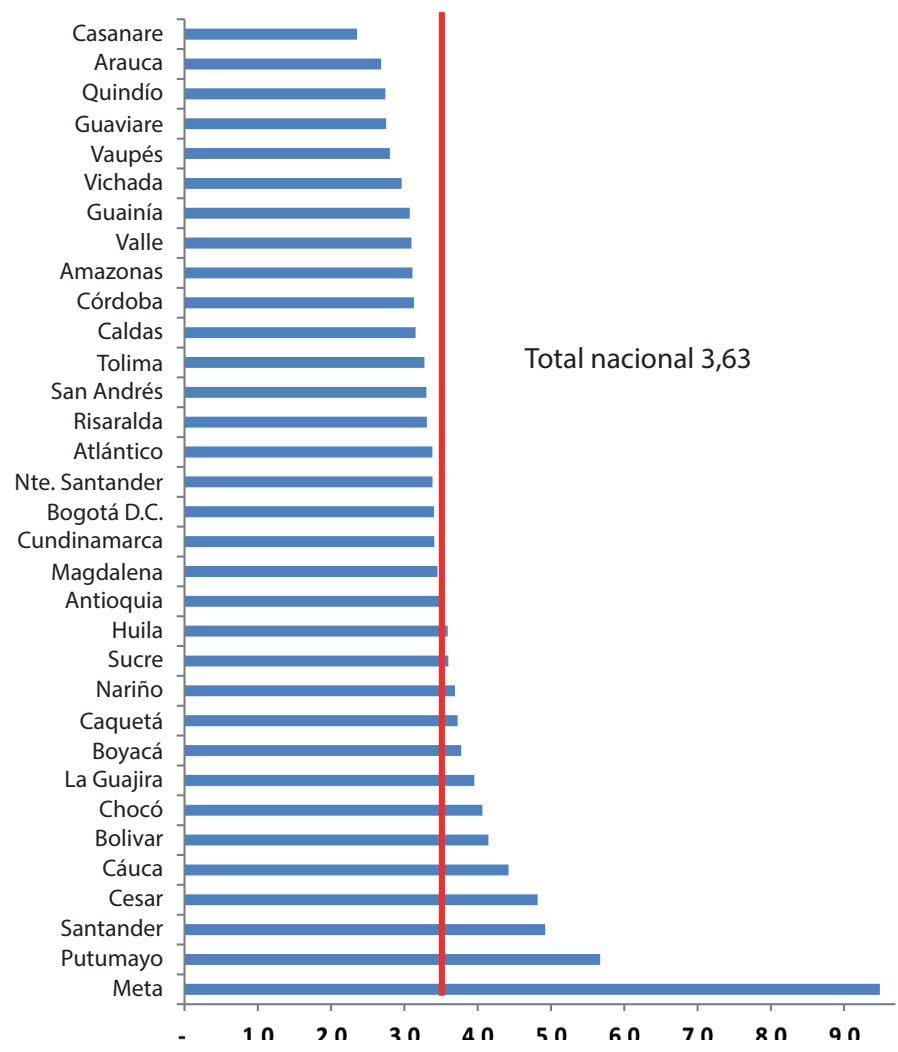

Fuente: elaboración de los autores con base en las Cuentas Nacionales. 
sigue siendo la economía más importante, con un peso de $24,9 \%$, aunque fue la región que mayor peso perdió respecto al 2000 (1,6 puntos); en tamaño le siguen Antioquia (13,5\%), Valle $(9,3 \%)$ y Santander (7,8\%), cuya participación aumentó en dos puntos en el mismo periodo. A este resultado le sigue Meta, que a su vez fue el departamento que más aumentó su peso relativo, al pasar de representar el 1,9\% del PIB en el 2000 a 5,1\% en 2014. Por su parte, las economías más pequeñas siguen siendo en esencia los antiguos territorios nacionales (Guaviare, Amazonas, Vichada, Guainía, Vaupés), con una participación exigua entre $0 \%$ y $0,1 \%$.

Este contexto, analizado por actividades, permite identificar en qué campos de la producción se concentran los liderazgos económicos regionales. Como se aprecia en la tabla 1, existe asimetría en la composición del PIB cuando se hace el contraste entre la representatividad en la actividad productiva del sector primario y los sectores secundario y terciario. Puede verse cómo Bogotá, Antioquia, Santander, Valle y Cundinamarca dominan la estructura en los sectores secundario y terciario, en tanto que Meta, Casanare y Antioquia lideran la producción primaria, específicamente en dos de los tres territorios, como resultado de la intensificación de la minería.

Por su parte, los aportes al crecimiento económico describen la influencia efectiva de cada región en la actividad productiva del país. Los resultados muestran cómo la diferencia en la variación porcentual del crecimiento entre 2013 y $2014(6,5 \%)$ y entre 2000 y 2001 (8,3\%) fue producto de que 23 de los 33 departamentos (incluido Bogotá) contribuyeran de manera efectiva menos en el último año, y que los aportes netos positivos estuvieran concentrados en pocos entes territoriales, principalmente Casanare, Guaviare, Huila y Putumayo. Esto último es explicado por el aporte de las actividades de construcción de edificaciones, obras civiles y servicios sociales comunales y personales, entre los cuales están los servicios de gobierno con un peso representativo (gráfica 2).

Tabla 1.

Liderazgos económicos regionales en 2014*

\begin{tabular}{|c|c|c|c|c|c|}
\hline \multicolumn{2}{|c|}{ Sector primario } & \multicolumn{2}{|c|}{ Sector secundario } & \multicolumn{2}{c|}{ Sector terciario } \\
\hline Meta & 24,7 & Bogotá & 18,6 & Bogotá & 33,3 \\
\hline Casanare & 11,0 & Antioquia & 16,7 & Antioquia & 13,7 \\
\hline Antioquia & 7,4 & Santander & 13,5 & Valle & 10,6 \\
\hline Cesar & 5,9 & Valle & 9,9 & Santander & 5,9 \\
\hline Santander & 5,9 & Cundinamarca & 6,6 & Cundinamarca & 4,4 \\
\hline Boyacá & 5,3 & Bolívar & 5,7 & Atlántico & 4,3 \\
\hline Cundinamarca & 4,5 & Atlántico & 5,2 & Bolívar & 3,7 \\
\hline La Guajira & 3,8 & Boyacá & 3,0 & Boyacá & 2,2 \\
\hline Huila & 3,4 & Cauca & 2,1 & Tolima & 1,9 \\
\hline Tolima & 3,2 & Tolima & 2,1 & Córdoba & 1,8 \\
\hline Valle & 3,2 & Huila & 2,0 & Norte Santander & 1,7 \\
\hline Resto & 21,7 & Resto & 14,5 & Resto & 16,5 \\
\hline Total del sector & 100 & Total del sector & 100 & Total del sector & 100 \\
\hline
\end{tabular}

* Peso del valor agregado sectorial en el PIB de cada departamento.

Fuente: cálculos de los autores con base en las Cuentas Nacionales. 
Aportes al crecimiento del PIB por departamento, 2000-2001 y 2013-2014*

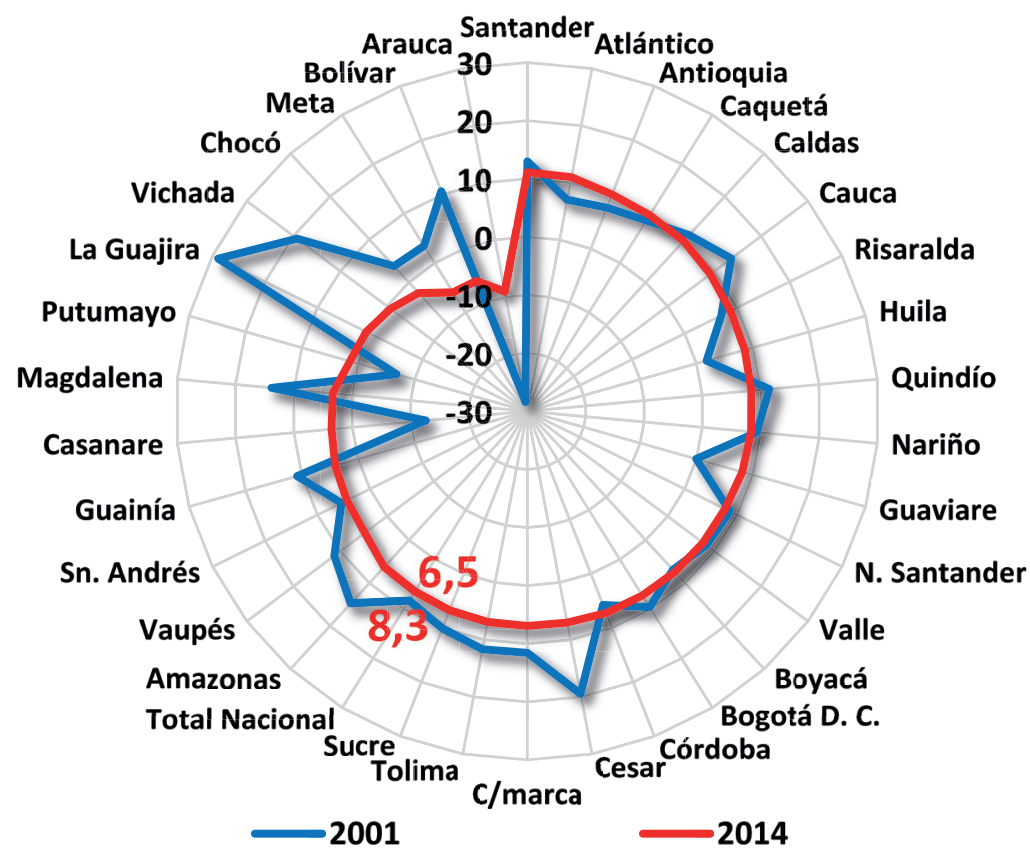

Crecimiento 2001-2000: 8.3\% Crecimiento 2014/2013: 6.5\%

* Puntos porcentuales a partir de valores de mercado.

Fuente: cálculos de los autores con base en las Cuentas Nacionales.

En suma, se advierte una economía nacional más grande, con economías regionales que han crecido significativamente en tamaño, aunque sus estructuras productivas se han mantenido relativamente estables. Asimismo, los territorios económicos líderes siguieron orientados a la producción de bienes y servicios del segundo y tercer sector, en tanto el sector primario se mantiene jalonado por la explotación de minas y canteras en un conjunto de regiones privilegiadas por la ventaja de disponer de riquezas naturales, con las cuales han ganado representatividad en el sistema productivo nacional. Por tanto, estos resultados conjugan un patrón regional dual que ampara la explotación de las ventajas competitivas de los departamentos, con una dinámica creciente de diversificación en otras actividades, algo propio de los retos que la nueva economía ha propiciado.

\section{Descripción de la estructura productiva departamental mediante análisis factorial}

Para explicar con mayor precisión el efecto particular que las diferentes actividades económicas han tenido durante el periodo de referencia en la orientación productiva regional, se recurrió al análisis factorial del valor agregado departamental. Así, se contrastaron sus resultados entre 2000 y 2014 mediante la aplicación del método ACP, cuyo protocolo estadístico tiene como fin evaluar el grado de relación lineal que presentan las diferentes actividades económicas en el ámbito departamental, identificando en este caso las actividades y los sectores que mayor influencia han tenido en la economía colombiana en el periodo de estudio.

Para tal efecto, el primer paso del método consiste en evaluar que los datos del valor 
agregado de las regiones tengan la estructura muestral adecuada para desarrollar el procedimiento estadístico referido en los dos periodos. Este paso se adelantó mediante la aplicación de la prueba Kaiser-Meyer-Olkin (KMO), la cual, como se constata en la tabla 2, evidencia bondad de ajuste dentro de los parámetros, así como significancia estadística, tanto en el 2000 como en 2014.

Por su parte, los indicadores de comunalidad del ACP para el 2000 reflejaron que en la extracción de señales de las diferentes actividades económicas por departamentos, las variables son bien explicadas a través de las componentes extraídas. Lo anterior se aprecia de manera explícita en la tabla 3 , donde se evidencia que todas las actividades económicas mantuvieron entre 2000 y 2014 un coeficiente de comunalidad alto y significativo (cercano a uno), salvo en los sectores agropecuario y minero, que presentaron cambios importantes en este periodo y aparecen distanciados de los resultados reportados por las demás actividades económicas.

Los coeficientes de extracción de los años analizados son altos y se ajustan a los requerimientos de representatividad que exige la prueba; particularmente resultan significativos para las actividades de transporte, almacenamiento y comunicaciones, comercio, restaurantes y hoteles, así como en los servicios sociales, comunales y personales; por ello, se infiere que en estos sectores se concentra en un grado importante la explicación de la dinámica productiva de los departamentos durante el periodo de estudio.

De conformidad con el orden de impacto que los diferentes sectores revelaron en el análisis

Tabla 2.

Prueba KMO y prueba de Bartlett

\begin{tabular}{|c|c|c|}
\hline Descripción & 2000 & $\mathbf{2 0 1 4}$ \\
\hline Medida de adecuación muestral de Kaiser-Meyer-Olkin & 0,814 & 0,837 \\
\hline Prueba de esfericidad de Bartlett (Chi-Cuadrado aprox) & 683,627 & 623,581 \\
\hline Grados de libertad (GI) & 36 & 36 \\
\hline Significancia estadística & 0,000 & 0,000 \\
\hline
\end{tabular}

Fuente: cálculos de los autores con base en las Cuentas Nacionales.

Tabla 3.

Indicadores de Comunalidad-ACP (2000 y 2014)

\begin{tabular}{|c|c|c|c|}
\hline Actividades económicas & Inicial & $\begin{array}{c}\text { Extracción } \\
2000\end{array}$ & $\begin{array}{c}\text { Extracción } \\
2014\end{array}$ \\
\hline Agropecuario & 1,000 & 0,553 & 0,740 \\
\hline Minería & 1,000 & 0,582 & 0,485 \\
\hline Industria & 1,000 & 0,975 & 0,872 \\
\hline Electricidad, gas, agua & 1,000 & 0,928 & 0,919 \\
\hline Construcción & 1,000 & 0,944 & 0,916 \\
\hline Comercio, hoteles y restaurantes & 1,000 & 0,995 & 0,978 \\
\hline Transporte, almacenamiento y comunicaciones & 1,000 & 0,981 & 0,979 \\
\hline Financiero & 1,000 & 0,957 & 0,950 \\
\hline Servicios sociales y comunales & 1,000 & 0,971 & 0,961 \\
\hline
\end{tabular}

Fuente: cálculos de los autores con base en las Cuentas Nacionales. 
de comunalidad anterior, mediante el ACP se conforman grupos específicos de actividades económicas denominados componentes, cuya influencia es significativa en la producción regional. De este modo, se redujo toda la información disponible a un espectro de variables que facilitan la interpretación del problema de estudio. En tal sentido, se detecta que en el análisis de la varianza del modelo, el componente 1 explica el comportamiento de la actividad económica departamental del 2000 en un 76,17\%, el componente 2 lo explica en un 11,45\% y un tercer componente lo hace en un 10,59\%. Se obtuvo así que estos tres componentes expliquen el problema de investigación en un $98,21 \%$, o, en otros términos, que la varianza total del fenómeno sea explicada en dicha proporción por los primeros tres componentes del valor agregado departamental (tabla 4).

Desde este mismo principio, en 2014 el componente 1 explica el comportamiento de la actividad económica departamental en un $73,03 \%$, el componente 2 lo hace en un 13,63\% y el componente 3 en un 9,64\%, lo que en suma combina la composición económica regional en $96,30 \%$ para el periodo en referencia (tabla 5).

Tabla 4.

Varianza total explicada (2000)

\begin{tabular}{|c|c|c|c|c|c|c|}
\hline \multirow{2}{*}{ Componente } & \multicolumn{3}{|c|}{ Autovalores iniciales } & Sumas de las saturaciones al cuadrado de la extracción \\
\cline { 2 - 7 } & Total & $\begin{array}{c}\text { (\%) de la } \\
\text { varianza }\end{array}$ & (\%) acumulado & Total & $\begin{array}{c}\text { (\%) de la } \\
\text { varianza }\end{array}$ & (\%) acumulado \\
\hline 1 & 6,855 & 76,170 & 76,170 & 6,855 & 76,170 & 76,170 \\
\hline 2 & 1,031 & 11,458 & 87,627 & 1,031 & & \\
\hline 3 & 0,953 & 10,592 & 98,219 & & & \\
\hline 4 & 0,090 & 0,998 & 99,217 & & & \\
\hline 5 & 0,039 & 0,433 & 99,651 & & & \\
\hline 6 & 0,017 & 0,186 & 99,836 & & & \\
\hline 7 & 0,009 & 0,098 & 99,934 & & & \\
\hline 8 & 0,004 & 0,041 & 99,975 & & & \\
\hline
\end{tabular}

Nota: el método de extracción es el ACP.

Fuente: cálculos de los autores con base en las Cuentas Nacionales.

Tabla 5.

Varianza total explicada (2014)

\begin{tabular}{|c|c|c|c|c|c|c|}
\hline \multirow{2}{*}{ Componente } & \multicolumn{3}{|c|}{ Autovalores iniciales } & \multicolumn{2}{c|}{ Sumas de las saturaciones al cuadrado de la extracción } \\
\cline { 2 - 7 } & Total & $\begin{array}{c}\text { (\%) de la } \\
\text { varianza }\end{array}$ & $\begin{array}{c}\text { (\%) } \\
\text { acumulado }\end{array}$ & Total & $\begin{array}{c}\text { (\%) de la } \\
\text { varianza }\end{array}$ & $\begin{array}{c}\text { (\%) } \\
\text { acumulado }\end{array}$ \\
\hline 1 & 6,573 & 73,036 & 73,036 & 6,573 & 13,630 & 73,036 \\
\hline 2 & 1,227 & 13,630 & 86,666 & 1,227 & & \\
\hline 3 & 0,868 & 9,643 & 96,309 & & & \\
\hline 4 & 0,194 & 2,158 & 98,466 & & & \\
\hline 5 & 0,078 & 0,868 & 99,335 & & & \\
\hline 6 & 0,048 & 0,531 & 99,866 & & & \\
\hline 7 & 0,006 & 0,067 & 99,933 & & & \\
\hline 9 & 0,004 & 0,046 & 99,979 & & & \\
\hline
\end{tabular}

Nota: el método de extracción es el ACP.

Fuente: cálculos de los autores con información de las Cuentas Nacionales. 
La anterior descripción puede comprobarse a partir del contraste del gráfica 3 de sedimentación, en el que se aprecia cómo a partir del cuarto punto (componente) no es representativa la explicación del comportamiento económico regional entre 2000 y 2014.

Los valores críticos de los dos primeros componentes representan de manera similar la economía de 2000 y 2014 (tabla 6), que son muy cercanos a uno para el primer componente y a cero en el segundo, en ambos periodos, para todas las actividades diferentes a las desarrolladas en el sector primario (agropecuario y minería). Esto explicaría que la economía colombiana tiene un sistema productivo dual en el que un conjunto focalizado de departamentos basan su actividad productiva en estos sectores, en tanto otro grupo importante de territorios enfocan su dinámica económica en las actividades del segundo y tercer sector de manera relativamente homogénea o común.

La anterior descripción es mucho más elocuente en el gráfica 4, que en dos dimensiones

Análisis de sedimentación 2000 y 2014
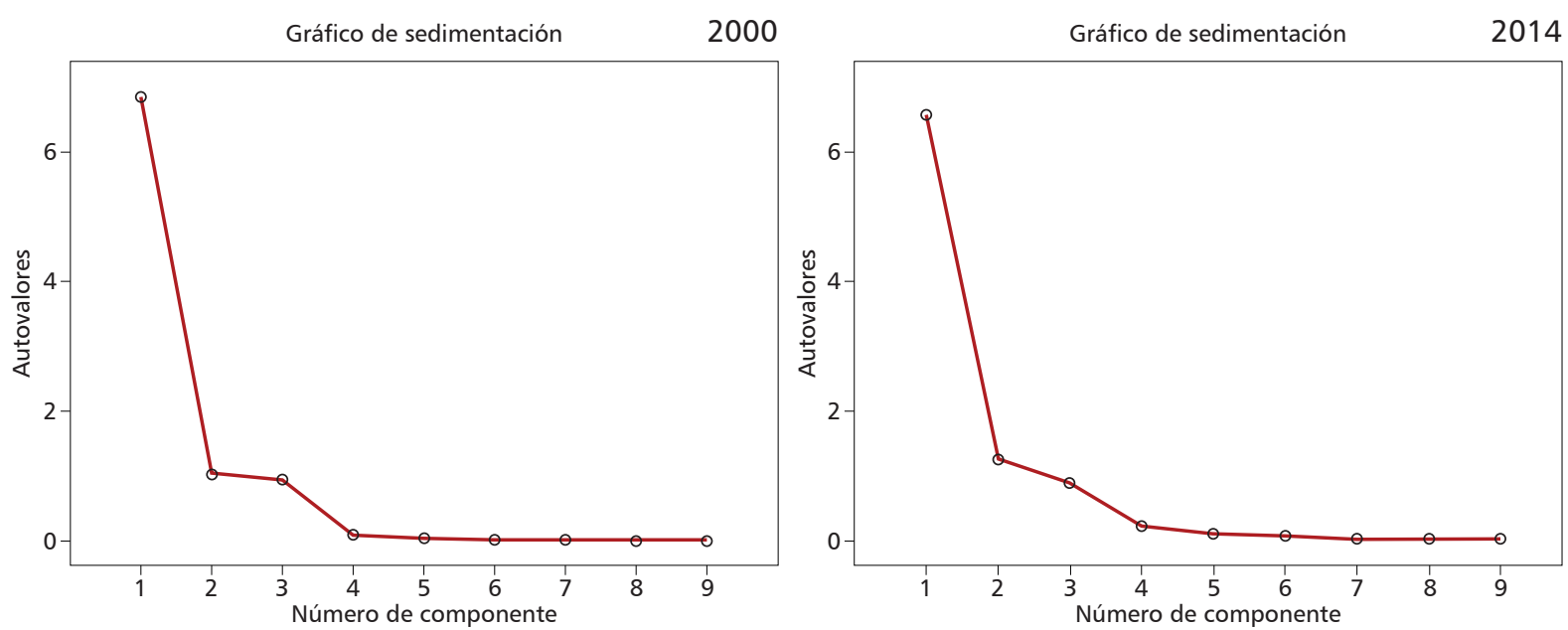

Fuente: cálculos de los autores con información de las Cuentas Nacionales.

Tabla 6.

Matriz de componentes principales (2000 y 2014)

\begin{tabular}{|c|c|c|c|c|}
\hline \multirow{2}{*}{ Actividades económicas } & \multicolumn{2}{|c|}{ Componentes 2000 } & \multicolumn{3}{|c|}{ Componentes 2014 } \\
\cline { 2 - 5 } & $\mathbf{1}$ & $\mathbf{2}$ & $\mathbf{1}$ & $\mathbf{2}$ \\
\hline Agropecuario & 0,382 & 0,638 & 0,435 & 0,742 \\
\hline Minería & $-0,092$ & 0,757 & $-0,026$ & 0,696 \\
\hline Industria & 0,987 & 0,036 & 0,925 & 0,126 \\
\hline Electricidad, gas, agua & 0,957 & 0,109 & 0,954 & 0,097 \\
\hline Construcción & 0,971 & $-0,021$ & 0,941 & 0,174 \\
\hline Comercio, hoteles y restaurantes & 0,998 & 0,013 & 0,978 & $-0,148$ \\
\hline Transporte, almacenamiento y comunicaciones & 0,988 & $-0,065$ & 0,982 & $-0,119$ \\
\hline Financiero & 0,967 & $-0,146$ & 0,940 & $-0,257$ \\
\hline Servicios sociales y comunales & 0,980 & $-0,104$ & 0,963 & $-0,182$ \\
\hline
\end{tabular}

Nota: el método de extracción es el ACP.

Fuente: Cálculos de los autores con información de las Cuentas Nacionales. 
Componentes principales regionales (2000 y 2014)
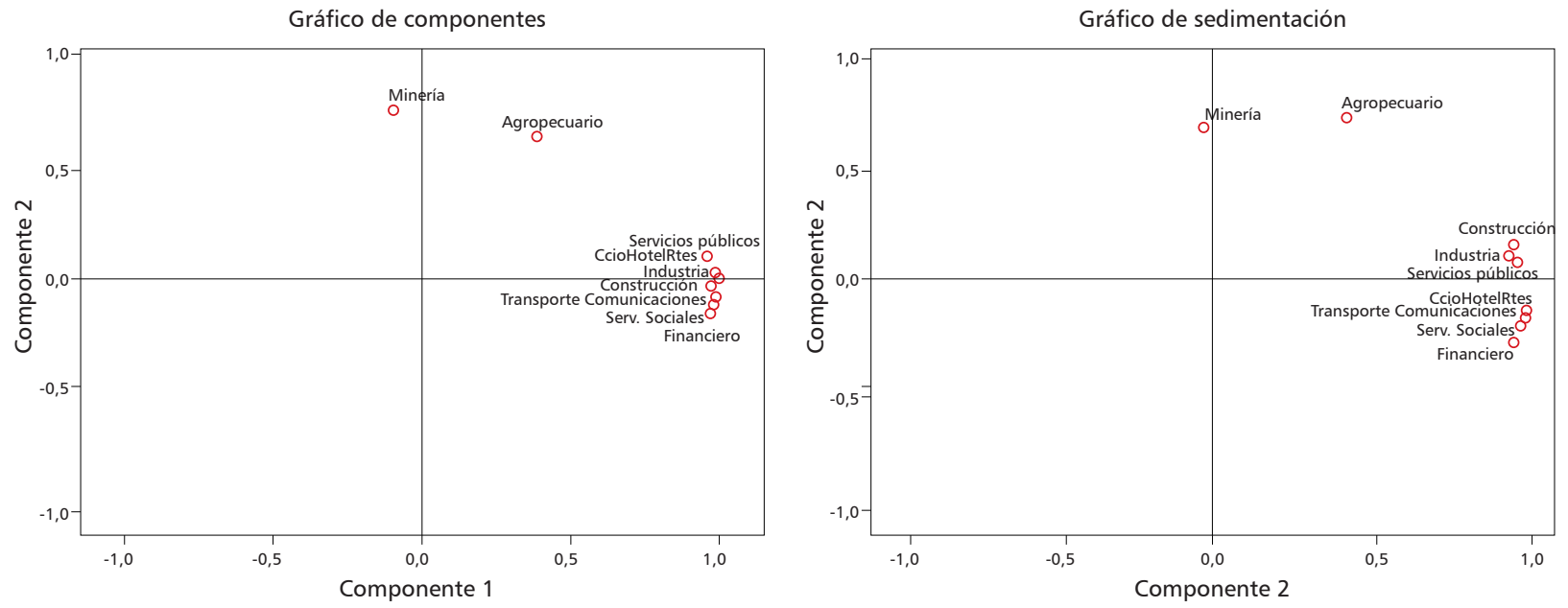

Fuente: cálculos de los autores con información de las Cuentas Nacionales.

evidencia cómo en los dos periodos de contraste del análisis factorial las economías regionales no han cambiado en forma importante sus patrones estructurales productivos, pues se mantiene de manera muy parecida el patrón de representación de las actividades minera y agropecuarias respecto del resto de actividades económicas.

Por tanto, la caracterización de las estructuras productivas de las economías regionales obtenida mediante el análisis factorial ACP no evidencia cambios representativos durante los últimos quince años; más bien manifiesta la existencia de un perfil económico estable de largo plazo en ellas.

Ahora bien, este modelo estadístico no permite identificar la orientación económica regional hacia la diversificación productiva o hacia la concentración en determinadas actividades (especialización), como las que ya se supone se presentan en el sector primario. La sección siguiente busca dar una respuesta a este interrogante mediante una metodología que complementa los instrumentos utilizados previamente; consiste en construir e interpretar los resultados de índices de especialización productiva que evalúen el cambio generado en este sentido entre los dos periodos de análisis.

\section{Especialización productiva regional en Colombia}

La orientación productiva de Colombia durante gran parte de la historia republicana ha sido típicamente agrícola y su proceso de diversificación ha sido lento, dado que el camino hacia la industrialización solo se dio con relativa fuerza mediante el modelo de sustitución de importaciones que la Comisión Económica para América Latina y el Caribe (Cepal) promovió conceptualmente en el continente hacia los años setenta del siglo pasado.

A partir de entonces, la incipiente industrialización del aparato económico ha pasado por diferentes y alternadas fases de dinamismo y crisis que no le han permitido al país consolidar un modelo manufacturero sustentable y con mayor oferta endógena. A ello se suma el redireccionamiento que afrontó el modelo económico, que pasó de ser 
proteccionista a estar sustentado en la apertura de fronteras para promover la competencia externa cuando la estructura de los factores de producción no había logrado ajustarse al nuevo paradigma del orden de los negocios en el ámbito mundial.

Por el mismo cambio, la interacción con los mercados externos y sus fluctuaciones hicieron que la economía aumentara progresivamente su vulnerabilidad a los choques internacionales, haciendo que estos no solo afectaran a la adolescente industria, sino que tuvieran también impacto en la dinámica del sector primario, que durante la historia había sido la fuente de crecimiento y de orientación al desarrollo.

Por tanto, evaluar los resultados de este proceso de reconversión productiva resulta fundamental, particularmente si se revisa en qué forma la dinámica del aparato empresarial ha logrado adaptarse a los cambios que exige un nuevo ordenamiento económico. Asimismo, este análisis adquiere mayor relevancia en la medida en que se adelante en un contexto de economía espacial y articulando las dos fases de análisis previas a esta última etapa: estructura y dinámica productiva sectorial regional y análisis factorial, de manera que se determinen no propiamente las condiciones del país, sino las de las propias regiones, que son en última instancia el nicho de los procesos de ubicación estratégica de factores y productos.
Para cumplir con este propósito, han sido construidos y contrastados los resultados del ISED por actividad económica tanto en 2000 como en 2014, con el fin de analizar cómo se ha adaptado la estructura productiva del país a las nuevas necesidades de la oferta en un periodo de tres lustros.

Con base en los resultados del ISED para 2000 (tabla 7), se aprecia cómo los primeros 12 departamentos ostentan un ISED de diversificación progresiva (avanzada) de su aparato productivo, en tanto que Boyacá, Meta, Cesar, Magdalena, Nariño y Quindío estarían en un tránsito hacia la diversificación plena. EI ISED de las siguientes siete entidades territoriales se encuentra en un rango medio entre la diversificación y la especialización, mientras que Arauca y Casanare muestran unas economías altamente especializadas, distantes de los resultados del resto regiones.

Quince años después se aprecia cómo durante 2014 el ISED sigue presentando a Antioquia $(9,4)$ como el departamento con mayor diversificación productiva, y a Casanare como el más especializado $(62,2)$, particularmente por la minería, en concordancia con lo descrito por el modelo ACP. Sin embargo, se aprecia un salto drástico hacia la especialización productiva por parte de Meta $(57,5)$ y Putumayo $(54,2)$, nuevamente por el auge de las actividades extractivas. Se registra también una leve mejora en el indicador de diversificación

Tabla 7.

Índice sintético de especialización productiva departamental (ISED), grandes ramas de actividad (2000)

\begin{tabular}{|c|c|c|c|c|c|}
\hline Departamento & ISED & Departamento & ISED & Departamento & ISED \\
\hline Antioquia & 7,9 & Cundinamarca & 20,7 & Caquetá & 37,2 \\
\hline Risaralda & 11,0 & Boyacá & 21,5 & Amazonas & 39,3 \\
\hline Valle & 12,9 & Meta & 23,1 & Chocó & 39,7 \\
\hline Caldas & 13,5 & Quindío & 25,1 & Vichada & 41,0 \\
\hline Atlántico & 14,3 & Nariño & 25,6 & Vaupés & 44,6 \\
\hline Santander & 15,1 & Cesar & 26,0 & Guaviare & 44,8 \\
\hline Tolima & 15,2 & Magdalena & 26,4 & La Guajira & 46,1 \\
\hline Bolívar & 15,5 & Sucre & 28,0 & San Andrés & 47,8 \\
\hline Norte de Santander & 15,7 & Córdoba & 29,4 & Guainía & 49,0 \\
\hline Bogotá & 16,5 & Huila & 29,7 & Arauca & 61,0 \\
\hline Cauca & 19,9 & Putumayo & 37,1 & Casanare & 73,2 \\
\hline
\end{tabular}

Fuente: cálculos de los autores con base en las Cuentas Nacionales. 
de Arauca $(53,7)$ y una tendencia a la diversificación progresiva de Córdoba, que pasó durante el periodo de un ISED de 29,4 a 19,2. En todo caso, salvo los departamentos identificados, el índice de especialización productiva no sufrió cambios sustanciales, por lo que se puede afirmar que en tres lustros la estructura productiva mantuvo el mismo patrón de comportamiento (tabla 8).
El contraste de resultados del ISED del 2000 respecto al 2014 destaca cómo en Meta y Putumayo hubo una marcada tendencia a la especialización productiva, Bogotá y Santander retrocedieron significativamente en su proceso de diversificación, mientras que Guaviare, Guainía y particularmente Córdoba impulsaron su sistema productivo hacia la diversificación (gráficas 5 y 6).

Tabla 8.

Índice sintético de especialización productiva departamental (ISED), grandes ramas de actividad (2014)

\begin{tabular}{|c|c|c|c|c|c|}
\hline Departamento & ISED & Departamento & ISED & Departamento & ISED \\
\hline Antioquia & 9,4 & Bogotá & 20,6 & Guaviare & 38,0 \\
\hline Risaralda & 10,4 & Cundinamarca & 22,1 & Guainía & 38,2 \\
\hline Atlántico & 12,6 & Quindío & 23,9 & Vichada & 38,8 \\
\hline Valle & 13,3 & Santander & 26,0 & San Andrés & 41,6 \\
\hline Caldas & 13,7 & Sucre & 26,6 & Vaupés & 42,7 \\
\hline Tolima & 15,9 & Huila & 26,6 & La Guajira & 43,9 \\
\hline Boyacá & 16,3 & Magdalena & 26,9 & Amazonas & 44,9 \\
\hline Norte de Santander & 17,9 & Nariño & 28,1 & Arauca & 53,7 \\
\hline Cauca & 18,8 & Cesar & 33,3 & Putumayo & 54,2 \\
\hline Córdoba & 19,2 & Caquetá & 34,5 & Meta & 57,5 \\
\hline Bolívar & 19,5 & Chocó & 37,3 & Casanare & 62,2 \\
\hline
\end{tabular}

Fuente: cálculos de los autores con base en las Cuentas Nacionales.

Gráfica 5.

Índice sintético de especialización productiva departamental (ISED)

2000

2014

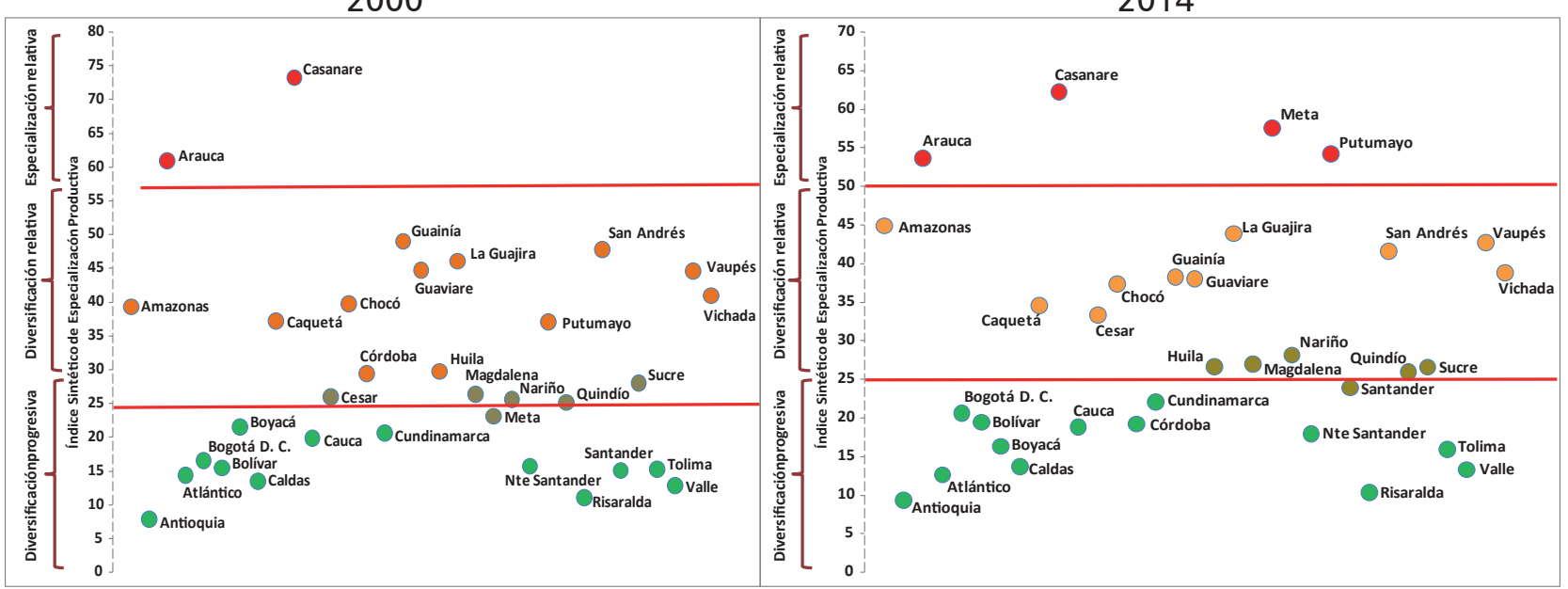

Fuente: cálculos de los autores con base en las Cuentas Nacionales 
Índice sintético de especialización productiva departamental (ISED), contraste 2000/2014

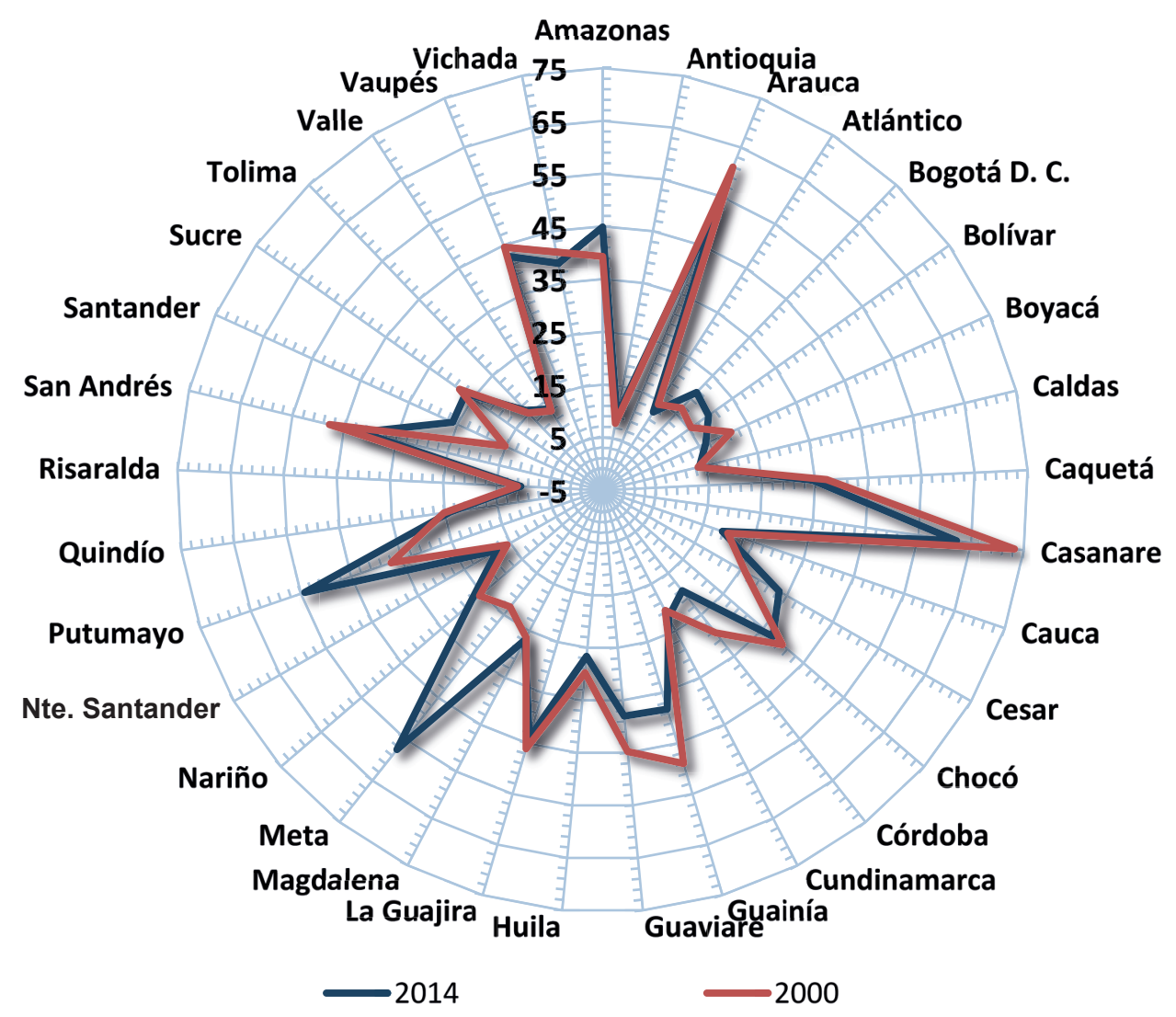

Fuente: cálculos de los autores con base en las Cuentas Nacionales.

Por tanto, la especialización productiva efectiva neta de Colombia, resultado de la diferencia entre el ISED del 2000 y el 2014, que representa un periodo de quince años, indica que diez y siete (17) de los treinta y tres (33) departamentos diversificaron durante este periodo su estructura productiva en algún grado (gráfica 7). De ellos se destacan los resultados de Casanare, cuya reducción en el ISED fue de 11,02 puntos, al pasar de un índice de 73,2 a 62,2 , que si bien es aún alto, muestra una eventual reducción de su dependencia económica en pocas fuentes de crecimiento; Guainía, que diversificó su actividad económica en 10,79 puntos, al pasar de un ISED de 49,0 a 38,2; y Córdoba, que llama poderosamente la atención, pues redujo su índice en 10,15 puntos, al pasar de un índice de 29,4 a
19,2, ubicándose así en el punto alto de la tabla de diversificación regional.

Por otra parte, el ISED en seis (6) departamentos mantuvo su promedio histórico, y en diez (10) regiones se evidenció una convergencia hacia la especialización en mayor o menor medida; Cesar, Santander, Putumayo y Meta fueron los departamentos más influenciados por esta situación.

Lo anterior, planteado esta vez por actividades económicas (gráfica 8), muestra para el periodo de referencia cómo la explotación de minas y canteras (línea roja) y las de servicios sociales, comunales y personales (línea amarilla) son las actividades económicas que más inciden en la especialización productiva regional. Particularmente la alta dependencia regional de las actividades de exploración y 
Índice sintético de especialización productiva departamental (ISED), efecto neto (2000-2014)

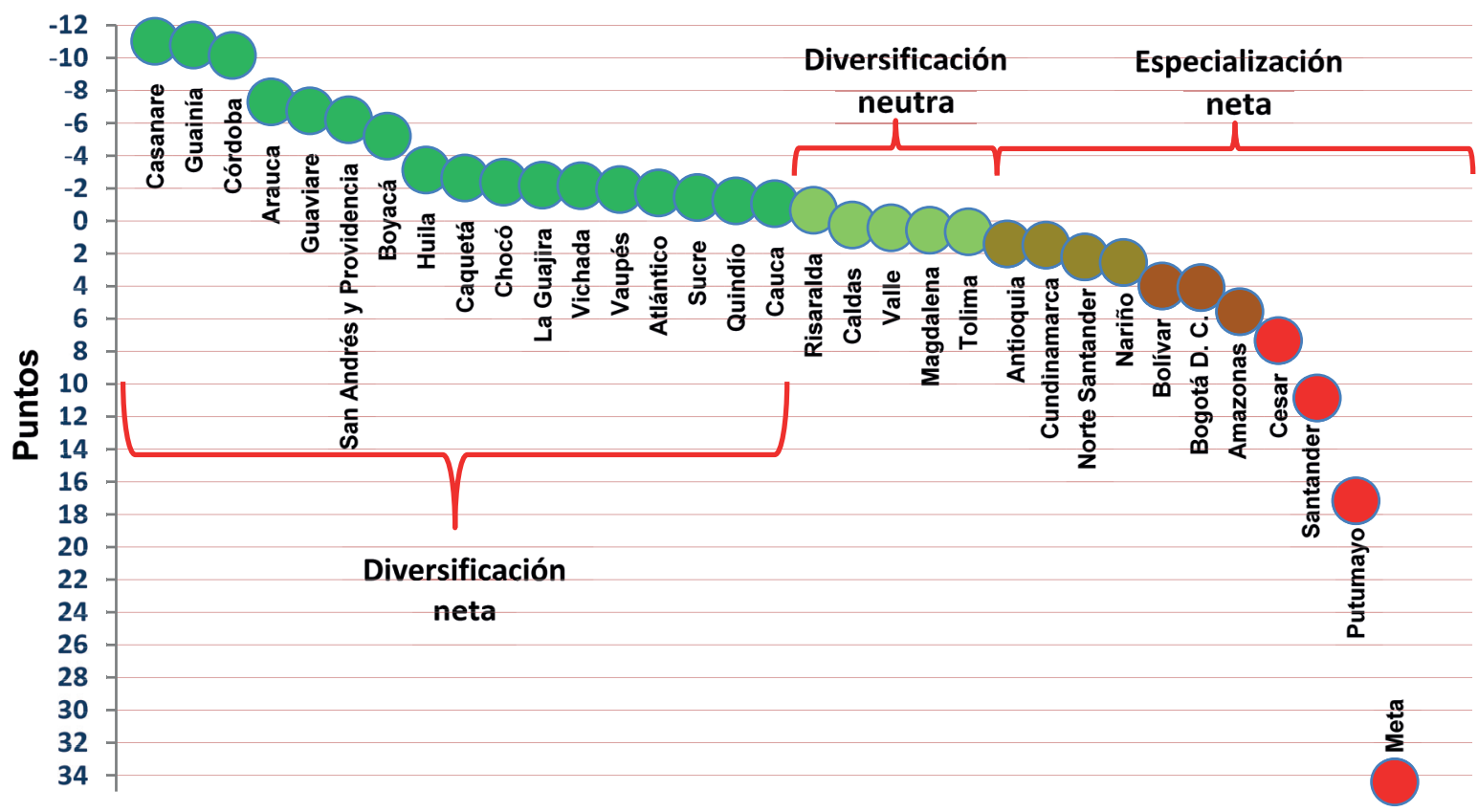

Fuente: cálculos de los autores con base en las Cuentas Nacionales.

explotación de hidrocarburos condujeron a Arauca, Casanare, Putumayo y Meta (con mayor impacto en las dos últimas regiones) a cambiar su orientación productiva durante el periodo de análisis, aspectos que son consistentes con los hallazgos identificados mediante el ACP

Por su parte, las actividades de servicios sociales -en las que se encuentran los servicios de administración pública, educación y esparcimiento de no mercado provistos por las entidades de gobierno y que presentaron una participación de 9,5\% en el PIB de dicho periodo- muestran desde otra perspectiva, y en línea con el estudio de Mendoza y Campo (2014), que existe una clara influencia de los servicios prestados por las instituciones públicas en el comportamiento de la actividad productiva regional. Este es un sector aportante altamente representativo en el producto departamental.

Al comparar los resultados del ISED por grupos ampliados de actividades (primarias, secundarias y terciarias), en contraste con el indicador departamental total, se aprecia cómo de los tres sectores, el secundario - que incluye la industria manufacturera, la producción de electricidad, gas y agua, la actividad edificadora y de obras civiles- es el que mejor refleja un sostenido proceso de diversificación productiva departamental en el periodo de estudio, aunque sin mayores cambios entre 2000 y 2014 al nivel de cada uno de los departamentos (gráfica 9).

Por otra parte, las actividades de servicios evidencian la mayor especialización productiva regional, en la medida en que son no solo en las que el ISED es más cercano a la unidad, sino porque siguen un patrón que converge al comportamiento del total nacional. En este sentido, se insiste que allí se encuentran reflejados los resultados de las actividades de administración pública, defensa, esparcimiento y otros servicios no mercantes, altamente influyentes en el patrón de especialización nacional (gráfica 8). 
Índice sintético de especialización productiva departamental (ISED), grandes ramas de actividad económica (2014)

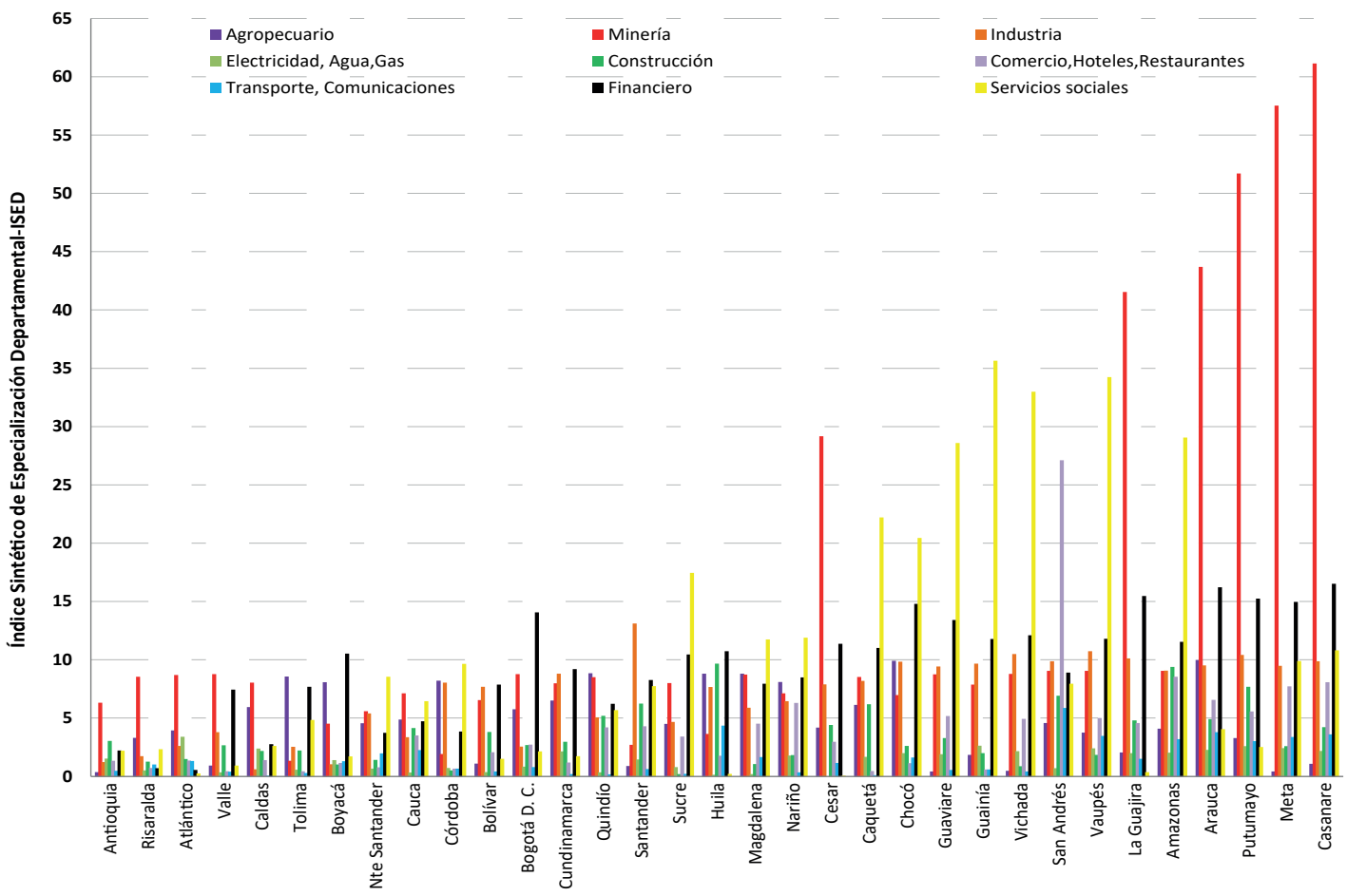

Fuente: cálculos de los autores con base en las Cuentas Nacionales.

Nótese que en el caso del sector primario (retomando los resultados del modelo ACP), los departamentos con mayor grado de especialización (ISED más cercano a la unidad) corresponden a regiones típicamente fuertes en la disponibilidad de recursos mineros (Arauca, Casanare, Guajira, Meta), en los que en algunos casos (Meta, Putumayo) nuevos hallazgos minerales durante el periodo hacen ver hoy a sus economías altamente especializadas.

El patrón de comportamiento del ISED en las actividades secundarias es relativamente homogéneo, lo cual no significa que el grado de industrialización sea avanzado o que se estén desarrollando en la misma magnitud grandes proyectos de construcción en todas las regiones; simplemente ello evidencia un progreso sostenido en la estructura productiva del país, en la que la socialización de necesidades ha ejercido presión para motivar a las entidades territoriales a implementar en mayor o menor escala actividades productivas asociadas a este macrosector, y con ello reducir la dependencia de este tipo de bienes/servicios originarios de los polos de desarrollo convencionales, que por muchos años han ejercido la función de proveedores de esta clase de productos característicos.

En suma, las evidencias encontradas mediante los diferentes caminos metodológicos abordados con esta investigación permiten reconocer que la dinámica productiva regional está evolucionando de manera positiva, aunque sus estructuras productivas se han mantenido relativamente estables en los últimos quince años; por ello, queda un ejercicio de reflexión económica para las regiones de cara a los cambios y las innovaciones de los negocios del mundo contemporáneo, así como frente a la respuesta que debe dar el modelo económico a la atención de las necesidades de los departamentos. Alrededor de este planteamiento y las inquietudes que suscita este trabajo, las reflexiones centrales que se expondrán a continuación se enfocarán en 
Índice sintético de especialización productiva departamental (ISED), sectores primario, secundario, terciario y total departamentos (2000-2014)

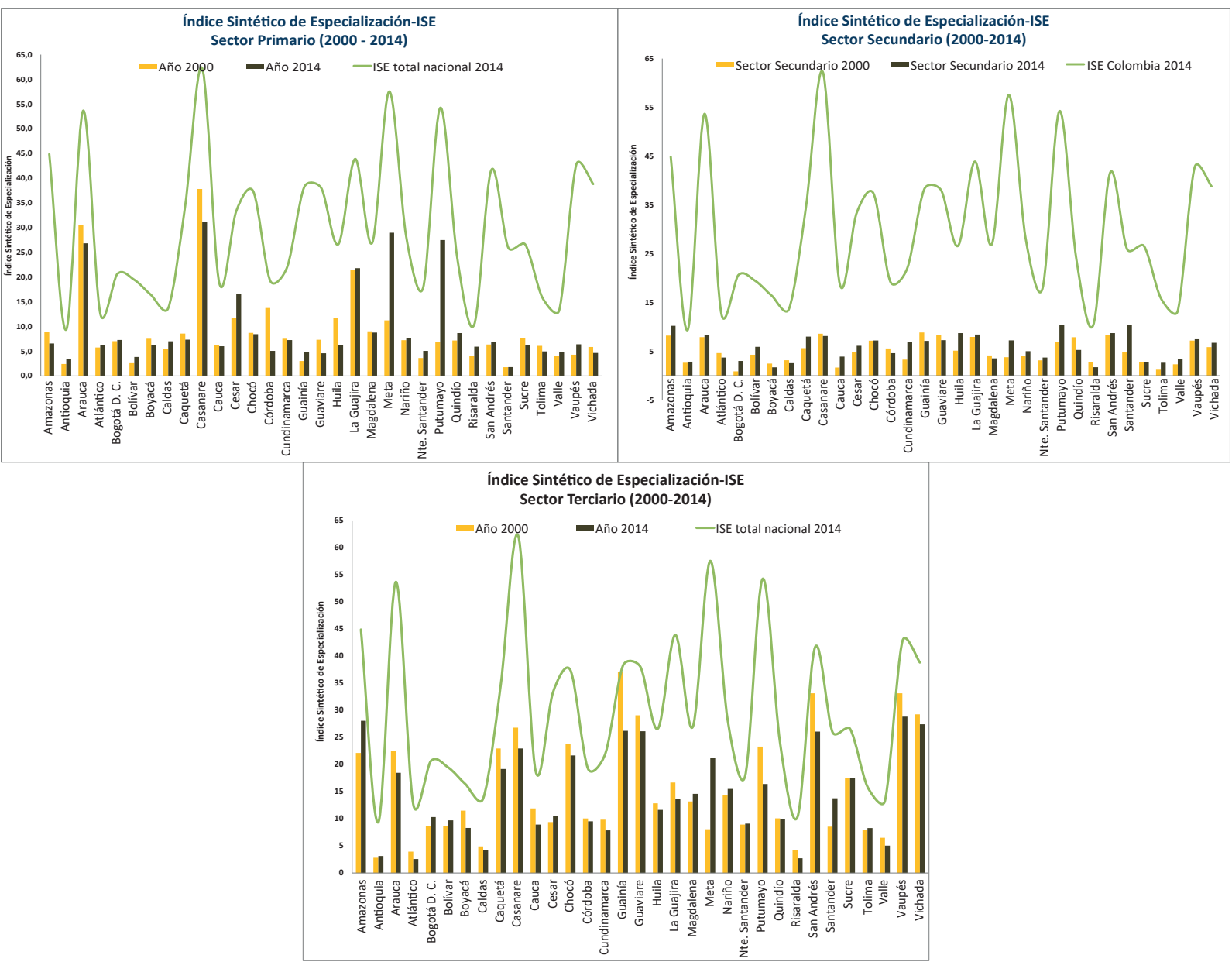

Fuente: cálculos de los autores con base en las Cuentas Nacionales.

describir los asuntos relacionados con el alcance del trabajo, la combinación de metodologías adoptadas, así como a los resultados derivados de este proceso.

\section{DISCUSIÓN}

\section{Sobre el alcance y objetivo del trabajo}

El análisis espacial y la geografía económica son temas que durante los últimos años han adquirido gran relevancia como base del diseño y la evaluación de políticas públicas, así como en la identificación de las fuentes de crecimiento de los países. La connotación territorial de los problemas económicos supone el estudio endógeno de las particularidades que los originan; se reconoce que los Estados típicamente están conformados por unidades territoriales heterogéneas que son influidas en su dinámica por un conjunto de circunstancias diversas.

Por tanto, el estudio de la especialización productiva desde un enfoque regional permite identificar las asimetrías económicas, así como las potencialidades regionales de cara a fortalecer, sobre la base de estas diferencias, los procesos de toma de decisiones de inversión y de perfilamiento 
territorial para orientar sus procesos productivos, superar las dificultades sociales y la inequidad y canalizar así su orientación a un estado superior de desarrollo.

En este sentido, el estudio adelantado hace un contraste complementario de metodologías que parte del análisis histórico de las estructuras productivas de los departamentos, para lo cual se emplea el sistema de cuentas nacionales regionales, que representa un sólido soporte del presente trabajo, por cuanto está sustentado en una base conceptual estructurada, íntegra y global de obligada aplicación internacional concebida por los principales organismos multilaterales (Naciones Unidas, FMI, Banco Mundial, OCDE, etc.). Además, sus resultados parten de un proceso de estandarización y armonización de las estadísticas —que son su fuente de cálculo-, de las buenas prácticas globales de producción de información estadística que hacen viable la comparabilidad internacional, así como del hecho de representar el sistema de información macroeconómica de hechos observados más riguroso y completo existente. Ello constituye la fuente básica para la toma de decisiones del Estado y la formulación de políticas públicas para la solución de los problemas de las regiones, en contexto con su realidad, pues es en ellas donde en última instancia se adelantan los procesos productivos.

Esta investigación ha contrastado el panorama de las estructuras económicas regionales desde sus actividades productivas, y para ello ha empleado de manera complementaria diferentes técnicas estadísticas en dos cortes de tiempo que cubren un periodo de quince años, con el fin de identificar los cambios en la composición y especialización productiva regional y ofrecer un panorama contextualizado de cómo los departamentos han afrontado los retos de un cambiante entorno mundial, dejando evidencia respecto a si se han preparado o rezagado de cara a los desafíos de la competencia y la atención de las demandas sociales locales.

\section{Respecto al método de trabajo}

La aplicación de un instrumento estadístico especializado para analizar la composición de las economías departamentales fue útil para precisar en qué sentido los resultados de las diferentes actividades productivas han conducido a cambios estructurales entre 2000 y 2014 . Para lograrlo, se emplearon técnicas de análisis factorial que basan su método en la descripción estructural de fenómenos, reduciendo su comportamiento a la interpretación de la combinación lineal de un conjunto simplificado de variables que lo afectan, de manera que tal interpretación se haga en términos comprensibles.

De esta línea metodológica, se optó por trabajar con el método de análisis de componentes principales (ACP), el cual permitió validar en el periodo 2000-2014 si existieron cambios en la composición estructural de las economías regionales, así como confirmar si prevalece alguna dependencia productiva en actividades económicas específicas en los territorios.

Como complemento de la aproximación mediante $A C P$, y con el fin de detectar eventuales cambios en la caracterización económica de las regiones en Colombia, fue recreado un panel de datos con los resultados del PIB departamental de los dos periodos de referencia. A partir de ellos fueron construidos índices sintéticos de especialización por región (ISED), instrumento que permitió plantear las dinámicas de la orientación productiva de los entes territoriales y contrastar la tendencia que ha seguido el país en torno a la diversificación de su producción.

La combinación de los citados instrumentos condujo a formular una serie de reflexiones en torno a la descripción de las estructuras productivas de los departamentos, identificar cambios y detectar ciertas particularidades de su origen. Asimismo, la confrontación del método adelantado con estudios similares arroja nueva evidencia de la manera como las regiones colombianas se han adaptado a los nuevos retos del orden económico mundial, al aprovechar sus ventajas competitivas y su dotación de factores. También ha permitido analizar cómo 
estas progresivamente han ido reconvirtiendo sus procesos productivos y se han adaptado a la competencia, al igual que revela el impacto que tiene el mantener ligado el sistema económico al suministro de riqueza por recursos naturales.

\section{Sobre los resultados y hallazgos}

Entre 2000 y el 2014 Colombia presentó un crecimiento económico sostenido con periodos de auge en la etapa superior del ciclo (2006-2007) y algunos años de rezago como resultado de la afectación producida por contagio de las crisis económicas propias e importadas (2000-2001 y 2009-2010). Sin embargo, la economía en su conjunto ha salido bien librada de los choques externos y ha logrado garantizar el equilibrio en sus indicadores líderes (crecimiento, inflación, empleo, tasas de interés, deuda, etc.), de manera que estos efectos se trasladasen de la manera más homogénea posible a las regiones.

De los hallazgos, se resalta que las regiones colombianas muestran un contraste entre las que aún se distinguen por destinar buena parte de su producción en actividades típicas primarias (agricultura, ganadería, minería) — particularmente porque la disponibilidad de recursos naturales para afrontarlo constituye una ventaja competitiva para orientar su desarrollo productivo y su identificación como región económica- $-y$ un segundo conjunto de entidades territoriales que desarrollan en forma alternativa el resto de actividades, en línea con un orden económico mundial que impulsa a los países a diversificar su oferta productiva y ser cada vez menos dependientes de recursos naturales específicos.

Con base en el hallazgo descrito, se ha detectado en Colombia un avance significativo en la diversificación de su producción, así como en la ampliación de su frontera productiva a un portafolio mayor de bienes y servicios para un grupo importante de departamentos. Se aprecia cómo durante el periodo de estudio, 17 de los 33 departamentos evidenciaron en términos netos una progresiva intensificación de diversificación productiva.
Por su parte, la especialización productiva, si bien se presentó en más departamentos durante 2014 respecto a lo reflejado en el 2000, fue particularmente especial en aquellos cuya fuente de crecimiento se soporta principalmente en la minería. Casanare, Meta, Putumayo y Arauca reflejaron cambios representativos hacia la especialización productiva, resultado del impulso que han tenido las actividades de exploración de hidrocarburos, cuya representatividad es significativa fuente de riqueza en estas economías regionales. EI ISED refleja que este tipo de actividades que forman valor agregado con base en una capacidad instalada intensiva en bienes de capital, y no en empleo, ha restringido la dinámica de la industria, una mayor diversificación y, en suma, el desarrollo de nuevas actividades económicas.

Contrario a lo que podría suponerse, el sector servicios constituye la mayor fuente de diversificación de las entidades territoriales, lo cual se refleja en los resultados del índice sintético de especialización departamental, principalmente en las actividades de comercio, restaurantes, hoteles, transporte, almacenamiento, comunicaciones y servicios sociales, comunales y personales (esta última incluye servicios de administración pública y otros de no mercado provistos por el gobierno, como educación, sanidad, esparcimiento, saneamiento. Ello explica en buena parte el estímulo que el gasto público ejerce en las regiones, porque de este se origina una porción representativa de las alternativas productivas y de ingreso de los departamentos.

\section{REFLEXIONES FINALES}

De conformidad con los hallazgos descritos, se advierten resultados interesantes en la evolución de la estructura y orientación productiva de las economías regionales, en los que si bien, para un periodo de quince años, no se reflejan cambios sustanciales, sí permiten destacar una marcada renovación en la orientación productiva de las entidades territoriales.

La evidencia detectada en torno a la tendencia a la diversificación productiva territorial en un 
poco más de la mitad de las regiones se enfoca en actividades de servicios antes que en producción de bienes; con ello se constata que dicho comportamiento es influido en forma importante por la orientación del gasto público local, tal como lo señalan Mendoza y Campo (2014).

Por otra parte, se aprecia que la dependencia de los recursos minerales como fuente de crecimiento impulsa el PIB de las entidades territoriales que están beneficiadas por esta ventaja natural, pero tiende a hacer más lenta la capacidad para diversificar su aparato productivo y conducir a estas economías al desarrollo. Si bien el selecto grupo de economías regionales que tendió a especializarse se duplicó (pasando de dos a cuatro), ello se originó fundamentalmente por la mayor eficiencia en la producción de hidrocarburos o la incorporación de nuevos descubrimientos, sin que necesariamente su capacidad potencial en el desarrollo de otras actividades se hubiese deteriorado. Meta fue el departamento que mejor reflejó esta particularidad entre 2000 y 2014.

En suma, se advierte que a los departamentos en Colombia les sigue costando separarse de las actividades primarias y del papel del gasto público como fuentes de crecimiento, de manera que propicien sus propios modelos locales de desarrollo productivo a partir de la explotación de sus potencialidades geográficas, políticas, formativas y productivas.

El reto para ellas consistirá en idear estrategias de largo plazo, en las que, sin renunciar a su orientación al sector primario tan estructural y arraigada, no riñan con una limitada dotación factorial (mano de obra cualificada, formación bruta de capital, etc.) que ha restringido su éxito como modelo de crecimiento, y en su lugar se fortalezcan las competencias que pueden generar, al enlazar dichas actividades con cadenas productivas en la industria manufacturera y los servicios que dinamicen el empleo y la inversión regional. En este sentido, si bien no era objeto de este trabajo, se abre una interesante línea de acción para que en una futura investigación se explore el sustento de los resultados obtenidos en torno a la localización y especialización productiva regional en Colombia, en contexto con los factores que limitan mejores indicadores de competitividad regional tanto en las regiones especializadas como las que han diversificado sus actividades económicas.

\section{REFERENCIAS}

1. Arias J. y Fortich F. (2010). El panorama teórico de la economía regional y los modelos de análisis territorial (Análisis de los modelos: relevancia, pertinencia y aplicabilidad). Finanzas y Política Económica, 2(2), 9-26.

2. Boissier, S. (1997). El vuelo de una cometa. Una metáfora para una teoría del desarrollo territorial. Santiago de Chile: Instituto Latinoamericano y del Caribe de Planificación Económica y Social (ILPES).

3. Boissier, S. (1980). Técnicas de análisis regional con información limitada. Santiago de Chile: Instituto Latinoamericano y del Caribe de Planificación Económica y Social (ILPES).

4. Campo, J. y Mendoza, H. (2014). Gasto público y crecimiento económico regional en Colombia (1984-2012). Bogotá: Universidad Católica de Colombia. Recuperado de http://portalweb.ucatolica.edu.co/easyWeb2/ economia/pages.php/menu/196/id/5196/content/documentos-de-trabajo/

5. Departamento Administrativo Nacional de Estadística (DANE) (2010). Dirección de Síntesis y Cuentas Nacionales. Cuentas Departamentales, Base 2005: resultados y cambios metodológicos. Recuperado de http://www.dane.gov.co/files/investigaciones/pib/departamentales/B_2005/Resultados_cambios_metodologicos.pdf 
6. Departamento Administrativo Nacional de Estadística (DANE) (2014). Cuentas Nacionales Departamentales. Recuperado de http://www.dane.gov.co/index.php/cuentas-economicas/cuentas -departamentales

7. Hernández, J. (2009). La composición del gasto público y el crecimiento económico. Análisis Económico, 24(55).

8. López, A. E. (1983). La conciencia regional en el proceso autonómico español. Madrid: Centro de Investigaciones Sociológicas.

9. Lozares, C. y López P. (1991). El Análisis de Componentes Principales: aplicación al análisis de datos secundarios. Barcelona: Universidad Autónoma de Barcelona. Recuperado de http://www.raco.cat/index.php/Papers/ article/download/25101/58447

10. Mendoza, H. y Campo, J. (2014). Postura fiscal y crecimiento económico regional en Colombia. Bogotá: Universidad Católica de Colombia. Recuperado de http://portalweb.ucatolica.edu.co/easyWeb2/economia/ pages.php/menu/196/id/5196/content/documentos-de-trabajo/

11. Mendoza, H. y Yanes, C. (2014). Impacto del gasto público en la dinámica económica regional. Finanzas y Política Económica, 6(1), 23-41.

12. Organización de Naciones Unidas (ONU) (2008). Sistema de Cuentas Nacionales 2008. Recuperado de http://unstats.un.org/unsd/nationalaccount/docs/SNA2008Spanish.pdf

13. Pinilla, D. Jiménez, J. y Montero R. (2013). Gasto público y crecimiento económico. Un estudio empírico para América Latina. Cuadernos de Economía, 32 (59).

14. Pons J. y Tirado D. (2009). Especialización productiva y asimetrías en las fluctuaciones económicas en las regiones europeas. Barcelona: Universidad de Barcelona. Recuperado de https://www.uclm.es/profesorado/obajo/ imagenes2/VIII\%20Jornadas/pdf/36\%20Pons.PDF

15. Rodríguez Nuño, V. (2005). Índice de especialización sectorial en los Estados miembros de la Unión Europea en 2003. Boletín Económico de ICE, 2839, 27-33. Recuperado de http://www.revistasice.com/ cachepdf/bice_2839_27-33_fd4e805ca7619cbfc9b750486f1ec49c.pdf

16. Sánchez,R.O.(2006).Crecimientoeconómicodepartamentalymigraciónen Colombia. Bogotá:DepartamentoNacional de Planeación. Recuperado de https://colaboracion.dnp.gov.co/CDT/Estudios\%20Econmicos/317.pdf 